\title{
Research on Applications of Information Technology in Sport Training
}

\author{
Shanyu Liu ${ }^{1, \text { a }}$ \\ ${ }^{1}$ Zhengzhou University of Industrial Technology, Zhengzhou, Henan, China, 451150 \\ ${ }^{a}$ email
}

Keywords: Information Technology, Sport Training, Sport Teaching

\begin{abstract}
With the rapid development of information technology, physical education using the information technology has become a trend in the field of physical education. This paper briefly introduces the concept of information technology applied in physical education, and then analyzes the advantages of information technology used in sports training. Based on the above analysis, we explore the key factors of the applications of information technology in sport training in order to provide some references for the relative researchers.
\end{abstract}

\section{Introduction}

For sports, teaching and training process is a very complex and rapid movement. Due to the characteristics of sports teaching and training, in this process can make the past action can be represented to the coaches and athletes, can the teaching and training of the coaches play an ideal reference. Especially in today's rapid development of information technology era of high-tech everywhere in the field of sports, computer technology, network technology, high-speed camera technology, wireless communication technology and other related technology books collection development, make full use of in the process of modern sports teaching and training in many coaches and athletes are very concerned about things. Use the computer to the text, pictures, sound, video and other media information in accordance with the teaching requirements of the organic combination and through the projector, audio display out of the teaching process. The application of information technology in teaching has a profound theoretical background. With the rapid development of information technology, information technology is now more and more people will be known as computer hardware resources and software resources, that information technology is a lot of disciplines and fields and cross integration of comprehensive technology. Computer operating system, electronic presentation technology, communication technology and modern multimedia video, audio, image editing technology, computer network technology to blend with each other, forming a large-scale information network across the world, information technology has become one of the core technology of today's global change. Today, people's daily lives and work are increasingly dependent on information technology. So is the education, the original teaching environment and teaching mode cannot meet the growing demand, only the application of information technology to the teaching process, in order to make education teaching has got great development in the modern information technology support.

\section{Advantages of Information Technology in Physical Education}

Provide Accurate Information. The traditional sports training adopt the method of "teacher demonstration. There are some limitations in this method. Information technology teaching provides the most standard, the most accurate information, can effectively solve these problems. First, the teacher's demonstration is not necessarily the most standard and most beautiful. Teachers 
can not in any discipline have the standard posture, even in the best subjects. There is still a gap between the standard degree of its action and national athletes, world-class athletes. The beauty of the teacher's demonstration directly determines the size of the student's interest in the subject. If we introduce information technology teaching, the use of the world's top athletes of the game video or training video as a demonstration of action, the standard of action and the beauty of the standard can give the students the most authoritative guidance. Second, the teacher's demonstration action is sometimes very short, difficult to break down. Students are often difficult to grasp the essentials of their action. In the teaching process, the whole process only lasts for a few seconds, and cannot be broken down. In this just a few seconds, the students cannot see all the action essentials, but also can not perceive the sequence of the parts. The teacher explained according to the video demonstration, the students according to the video and explain the essentials of the experience, the details of the action with the teachers, this can greatly improve the teaching efficiency, reduce the difficulty of training students. Because of the information technology teaching only file playback, the file can be transmitted to the students. Students can continue to watch, strengthen the experience, on the basis of clear action representation to improve learning quality.

Stimulate Students' Interest. Interest is the best teacher. When the students are interested in a certain thing, learning enthusiasm, learning time increased, learning efficiency, learning effect will be very good. However, in the traditional sports training, the use of either teacher demonstration student exercises, or blackboard and chalk theory courses, it is difficult to stimulate students' interest. When we introduce the information technology into the physical training, the text, pictures, audio, video and other forms of information will stimulate the student's brain. The information technology is illustrated, with a combination of static and dynamic, with sensual image of concrete, easy operation and other characteristics can effectively attract the students' attention. At the same time, we can use information technology to use some new teaching methods to stimulate students' interest in learning. With information technology in sports training, not only to create a lively and vivid, rich and colorful teaching, but also can create a personalized and diversified classroom teaching. In such sports training, students feel not hard, more happiness and harvest. In the martial arts teaching for example, teachers can take the martial arts students, made into a video in the courseware. Students can watch their classmates or martial arts, martial arts to understand the situation of their own, while listening to the teacher comments, pointed out the inadequacies in the wonderful martial arts, martial arts promotion skills. This method can greatly mobilize the enthusiasm of students learning. Integrating information technology into physical training can effectively stimulate students' interest in learning physical education. The application of information technology in the teaching of physical education, not only changes the traditional teaching methods, but also pays more attention to the cultivation of students' individuality in teaching ideas. Under the guidance of a variety of interesting teaching materials, rich and colorful interactive communication, it can be a greater degree of this to stimulate students' interest in learning, increase the enthusiasm of the students to the physical education curriculum. In addition, the information technology to assist physical education teaching, through the teaching concept of the implantation, training students lifelong learning, happy learning concept, the students have a very important physical health significance.

Improve Comprehensive Quality. Using the information technology to carry on the physical education teaching, not only can improve the student's sports skill, but also can effectively improve the students ability to use the computer and analysis summary ability and so on. Students can decompose the standard action by information technology software, modification and combination of playback parameters using the software, so that students can see not only is a standard action 
demonstration, is more of a group or several groups of action demonstration. Students from the experience of the pros and cons of action can deepen the understanding of the standard action. In the sports teaching, this technique will serve as an auxiliary teaching mode can make teaching objectives more clear and clear, through the comparison and analysis of the technical level, teachers and students can make clear the differences of action, thus can establish a better understanding of the sport idea. In addition, the use of information technology to carry out physical education can also enhance the students' ability to analyze and summarize. For more difficult action, the teacher can show the standard action to allow students to observe, analyze, summarize the action essentials, and the results of the. Teachers comment on the results of the analysis and supplement. This method not only deepens the students' impression, but also trains the students' ability of observation, analysis and expression.

\section{Key Points of Applications of Information Technology in Physical Education}

Leaders' Attention. With the development of the times and the progress of science and technology, information technology has been gradually applied to the cause of education, changed the traditional teaching of the blackboard and chalk, inspired the interest of students, and improves the quality of teaching. However, most of the application of information technology is limited to the subjects of cultural courses, and it is seldom used in sports teaching. This is very relevant to the importance of school leadership in the use of information technology in the teaching of sports. School leaders often think that sports is to rely on hard work, do not need to rely on Teachers' demonstration, teaching with information technology, but do not need to establish the teaching classroom specialized in sports information technology, manpower, material and financial resources invested is obviously insufficient, the majority of sports teaching are still using the traditional teaching mode, or even use the information technology teaching model but also because the facilities are not up to the high standard and cannot achieve good results. The importance of leadership is the key factor for the application of information technology in physical education. In fact, all the school outstanding performance, the information technology in the sports teaching effect, some school leaders attach importance to is the application of information technology in sports of the school; Information technology in all aspects of physical education teaching achievements, school leaders must be more requirements on information technology features, are not familiar with the superiority the application of information technology in sports teaching is not clear. School leaders should first improve their own quality. We should strengthen the awareness of the importance of the use of information technology in sports teaching. Leaders only recognize that modern sports teaching must use information technology to teaching, in order to better teach students action essentials, in order to better stimulate students' interest, in order to better increase the course capacity.

Teachers' Capacity. The quality of teachers is another important factor of information technology in physical training. This does not mean that the quality of teachers, physical education teachers moral quality, is not familiar with the situation of physical education teachers refers to the course, but refers to the physical education teachers skilled use of modern equipment and information technology for teaching quality. Physical education teachers are the executive of physical education teaching, and their ability to use information technology directly determines the role of information technology in physical education teaching. Some teachers do not see the great role of information technology in sports training, to teaching the use of information technology, is still following the traditional blackboard and chalk, personal demonstration of the old ways; some teachers Although the role of information technology in sports training in the recognition is very 
clear, but the problem with age, energy and habits on the use of information technology skills are not skilled, rarely used in teaching. Therefore, we hand in the introduction of physical education teachers. It should be the introduction of high-quality sports talents, the use of information technology; on the other hand, the existing physical education teachers, we should organize the experience of the physical education teachers training information technology and information technology, information technology teaching courseware concepts and skills. Physical education teachers should strengthen their self-cultivation, enhance their ability to accept new things, the courage to explore the teaching path, to fully grasp, the degree of proficiency, as both physical skills, excellent teachers and understand the modern science and technology.

Perfect Facilities. Perfect facility is one of the key factors to integrate information technology into physical training. There are a lot of time, due to the lack of financial investment and related sports teaching facilities, the impact of physical education. For sports training, the information technology teaching is higher than the requirements of the general discipline of information technology teaching. For the general subject, the information technology teaching only requires a common integrated information technology, information technology with the commonly used equipment. However, for sports training, the need for specialized information technology classrooms should be set up in the stadium. For example, set up a dedicated information technology classroom in the badminton hall, swimming pool and information technology special also opened in the swimming pool. This can greatly reduce the teachers and students in the theoretical and practical courses between the run, making the theoretical and practical courses in a unified, eliminate the waste of time, improve the efficiency of teaching. Sound facilities include not only dedicated information technology classrooms, but also the latest sports courseware and video. PE teachers should also be based on the development and progress of the times, constantly update the courseware, make students understand the latest sports knowledge, familiar with the latest sports skills, watch the latest sports and study the new sports teaching, so as to greatly stimulate the interest of students, let students actively participate in sports.

\section{Conclusion}

At present, information technology has been widely used in cultural teaching activities. However, the application of sports training is not very common. The information technology in the sports training and education has the incomparable superiority of the traditional teaching. We should strengthen leadership attention, improve the teachers' quality and perfect the teaching facilities in order to promote information technology in sports education.

\section{References}

[1] Tang Xuejun, Modern Computer, Vol. 31 (2014) No 6, p.66-67

[2] Lin Jian, Electronic Test, Vol. 21 (2014) No 9, p.134-135

[3] Zhang Qingwei, Wang Xiaojing, China Educational Technology \& Equipment, Vol. 30 (2016) No 3, p.118-119

[4] Hao Xuejuan, Journal of Sports Adult Education, Vol. 25 (2009) No 9, p.59-60 